\title{
AVALIAÇÃO DA APRENDIZAGEM DO HANDEBOL POR JOVENS ENTRE 11 E 14 ANOS A PARTIR DO MÉTODO SITUACIONAL
}

\author{
Giuliano Salera Ricci \\ Universidade Estadual de Campinas, Campinas, São Paulo, Brasil \\ Heloisa Helena Baldy dos Reis \\ Universidade Estadual de Campinas, Campinas, São Paulo, Brasil \\ Rafael Pombo Menezes \\ Universidade Estadual de Campinas, Campinas, São Paulo, Brasil \\ Clodoaldo José Dechechi \\ Centro Universitário Estácio de Sá, Ourinhos, São Paulo, Brasil \\ Cintia Ramari \\ Universidade Estadual de Campinas, Campinas, São Paulo, Brasil
}

Resumo:O ensino a partir do método situacional não tem como objetivo a maestria técnica e sim o entendimento da tática do jogo coletivo, fazendo com que os jogadores se habituem às situações-problema, percebam que há diversas formas de solucioná-las e selecionem a resposta mais adequada. A presente pesquisa teve como objetivo avaliar as influências do método situacional no ensino das capacidades técnicas e táticas do handebol utilizando-se dos testes propostos em Greco (1995) e também a partir dos níveis de jogo propostos por Garganta (1995). Após a aplicação de um programa de ensino-aprendizagem-treinamento de 32 sessões, observou-se uma melhoria da capacidade tática dos jogadores e a manutenção de sua capacidade técnica, o que demonstra a eficácia do método para o aprendizado tático do jogo.

Palavras-chave: Jogos Esportivos Coletivos - Handebol - Método Situacional

\section{Introdução}

No universo dos esportes coletivos, a dimensão tática ocupa o núcleo da estrutura de rendimento, com as demais tendo a função de cooperar no intuito de facultarem o acesso a desempenhos táticos de nível cada vez mais elevado (GARGANTA, 1995). Assim, torna-se fundamental que, na iniciação esportiva, o jogador tome conhecimento de como se comportar inteligentemente nos jogos coletivos e não, necessariamente, que este possua uma maestria de gestos inerentes ao alto rendimento (técnica) no momento da iniciação esportiva, ou seja, é de extremo interesse que o aprendiz saiba o que fazer perante as

Pensar a Prática, Goiânia, v. 14, n. 1, p. 1-18, jan./abr. 2011 
imprevisibilidades apresentadas pelas situações do jogo coletivo, não importando a habilidade técnica utilizada, contanto que esse seja eficaz em relação ao alcance do objetivo proposto.

Segundo Graça (1995), é essencial que os aprendizes dominem "o quê, quando e porquê" dentro do jogo, concernentes às habilidades abertas, que consistem na capacidade de responder a um problema que pode ter mais de uma solução correta, não apenas uma única forma rígida de execução, e não que dominem inicialmente o "como" que se relaciona às habilidades fechadas, que são as técnicas rígidas de execução de fundamentos do jogo. É óbvio que o domínio desse "como" influenciará na realização das habilidades abertas, contudo deve ser considerado que o aprendiz já detenha habilidades motoras e que uma operacionalização destas seja secundária se comparada à necessidade de conhecer como se portar inteligentemente nos jogos esportivos coletivos.

Com isso se demonstra que o aprendizado deve basear-se primeiramente na tática, sendo esta entendida como a arte de sincronizar ações às situações proposta pelo meio, organizando-se individual e coletivamente, utilizando meios específicos de ação, sempre objetivando o êxito coletivo (FALKOWSKI, 1979), ou mesmo como uma capacidade sensocognitiva que se baseia em processos psicofisiológicos, ou seja, captação e transmissão das informações providas pelo meio, interpretação destas, elaboração de respostas tendo como base conhecimentos pré-adquiridos e execução da resposta mais adequada encontrada, evidenciando-se a importância das experiências anteriores e da concepção que o jogador possui do jogo para poder atuar taticamente perante as imprevisibilidades estruturais dos jogos esportivos coletivos (GRECO, 2000a).

Com isso, é fundamental que os métodos de ensino-aprendizagem-treinamento ${ }^{1}$ sejam promotores de vivências táticas aos aprendizes, para que estes futuramente possuam respostas mais inteligentes (GRECO, 1988) e mais adequadas para a resolução dos problemas apresentados pelos jogos esportivos coletivos.

Propostas como as de Greco e Benda (1998) e Kröger e Roth (2002), que têm como seus princípios básicos o jogo, o treinamento coordenativo e o desenvolvimento de habilidades para superação dos problemas táticos pertencentes aos jogos esportivos coletivos, mostram-se coerentes para o ensino dos jogos esportivos. O objetivo dessas propostas é fazer com que os aprendizes vivenciem uma variedade de movimentos, aprendam a jogar livremente sem cobranças que visem ao alcance de um rendimento precoce e desnecessário, que possam testar e compreender diferentes situações táticas, adquirindo assim experiências de forma incidental, consolidando a aprendizagem. Assim, a perfeição da técnica não é o tema central, sendo o mais importante o aprender jogando (GRECO; BENDA, 1998), pois segundo Paes (2001) é preciso jogar para aprender, e não aprender para jogar.

\footnotetext{
1 Nomeia-se aqui o processo como "processo de ensino-aprendizagem-treinamento", pois se acredita que "constitui-se de uma trilogia, onde a aprendizagem e o ensino concretizam-se através do treinamento" (GRECO, 1995).
}

Pensar a Prática, Goiânia, v. 14, n. 1, p. 1-18, jan./abr. 2011 
Portanto, o objetivo deste trabalho é avaliar as influências de um método de ensinoaprendizagem-treinamento baseado na tática (na fase de orientação ${ }^{2}$ ), em detrimento da perfeição técnica, como ainda é feito usualmente, demonstrando a eficiência desse método, e também analisar suas implicações nas capacidades técnico-táticas dos jogadores.

\section{Sobre os sujeitos, os procedimentos de ensino e os testes}

Sujeitos e local de desenvolvimento

A presente pesquisa mesmo sendo do campo das humanidades, seguiu os requisitos da ética em pesquisa do Conselho Nacional de Saúde (1996). Ela foi desenvolvida em uma escola de ensino fundamental da rede municipal de ensino da cidade de Campinas - SP. A escola foi escolhida pelo critério de acessibilidade ${ }^{3}$. A faixa etária que compreende os alunos em escolarização no ensino fundamental era justamente pertencente ao grupo que havíamos delimitado para a pesquisa, ou seja, alunos (sujeitos) em idade aproximada de 12 a 14 anos (+ ou - 1 ano).

Após nossa proposta ter sido aprovada pela direção da escola, foi iniciada a divulgação dela em todas as classes de $6^{\circ}$ ao $9^{\circ}$ ano do período matutino, pois as atividades pedagógicas seriam desenvolvidas no período vespertino (horário em que havia disponibilidade da quadra poliesportiva da escola), duas vezes por semana, como atividade extracurricular. Foi esclarecido aos alunos que as atividades propostas faziam parte de um projeto da universidade e que todos estavam convidados, porém havia algumas regras para a participação como: a anuência dos pais e a assiduidade nas aulas. Feito esse esclarecimento, foi marcado o início das atividades.

Pudemos contar efetivamente para a pesquisa com sete alunos ${ }^{4}$ com idades entre 11 e 14 anos, sendo seis do sexo feminino e um do sexo masculino. Os outros quiseram participar da atividade, com a anuência da direção, mas não quiseram participar da pesquisa, podendo dessa forma colaborar na realização das atividades propostas.

As atividades pedagógicas propostas para o ensino do handebol foram realizadas em 32 sessões de treinamento, com a frequência de duas sessões por semana, com duração de uma hora e trinta minutos no período de oito meses (no período houve recesso escolar de três meses correspondente as férias de verão).

\footnotetext{
2 Fase do treinamento que, segundo Greco e Benda (1998) compreende a faixa etária de 12 a 14 anos. 3 Outras duas escolas foram contatadas para a realização da pesquisa mas negaram nossa solicitação; a primeira, com o argumento de que não havia disponibilidade de espaço para a realização dela, e na segunda a direção mostrou-se contrária a parcerias com a universidade, pois segundo ela esse tipo de relação não traz nenhum benefício para a escola; apesar da nossa disposição para o debate sobre o tema, a direção foi irredutível em sua negativa.

$4 \quad$ Apenas esses conseguiram que seus pais ou responsáveis legais autorizassem sua participação devolvendo o termo assinado.
}

Pensar a Prática, Goiânia, v. 14, n. 1, p. 1-18, jan./abr. 2011 
Sobre o método de ensino-aprendizagem-treinamento

O ensino dos jogos coletivos esportivizados pode ocorrer de formas variadas, mas tradicionalmente acontece por meio de métodos como o analítico e o global.

O método analítico tem como apoio a teoria associacionista, que preconiza que uma destreza motora deve ser ensinada em partes para depois uni-las, partindo da prerrogativa de que as partes são aprendidas de acordo com algum critério ou um número fixo de ensaios isolados, sendo que podem ser apresentados aos alunos vários segmentos do todo, porém sempre de forma progressiva (do fácil para o difícil). Esse método apresenta como vantagem uma rápida melhora da técnica, o que gera certo grau de motivação por parte do aluno; é também um método de fácil assimilação dos conteúdos técnicos do esporte, porém tem como desvantagem a mecanização das ações dos jogadores, já que considera que o jogo é apenas uma soma de suas partes, fazendo com que o aluno sempre se confronte com situações-problema de uma mesma forma, normalmente em situação estática e predeterminada (GRECO, 2000b), situações completamente distintas das exigidas no transcurso do jogo (esporte coletivo), no qual as situações-problema são imprevisíveis.

Já o método global se fundamenta na percepção dos estímulos não como uma soma das partes, mas sim como um conjunto organizado, no qual são elaboradas simplificações das situações reais do jogo - muito próximas do jogo formal, em que a dificuldade é adequada aos praticantes -, como campo de jogo e tamanho dos alvos, e é progressiva, até que se chegue ao jogo formal (GRECO, 2000b). A crítica a esse método é a grande quantidade de informações para a prática dos jogos, pois eles devem ser semelhantes ao jogo formal.

Em contraposição a esses, há outras formas de ensino dos jogos coletivos esportivos que se baseiam no princípio tático do jogo e se utilizam dos jogos situacionais e reduzidos. Trataremos aqui particularmente dos que se utilizam dos jogos situacionais, tendo como princípio o ensino das particularidades de situações táticas presentes no jogo formal, porém as suas atividades podem permitir também um aprimoramento técnico, já que os elementos do jogo passam a ser denominados neste como técnico-táticos. Ou seja, o princípio norteador do método é o tático, no entanto para a realização das decisões táticas é necessário uma ação técnico-tática.

A estratégia utilizada para tal é a prática de jogos situacionais, pois se acredita que por meio de atividades dessa natureza se possibilitará o aumento do repertório de soluções táticas dos aprendizes por meio da familiarização destes com as situações-problema dos jogos coletivos esportivizados.

No método situacional sempre são consideradas várias soluções para cada situaçãoproblema, existem possibilidades de escolha de uma solução mais adequada (correta), menos adequada (aceitável) e a escolha indesejada (errada) de situações inadequadas para os problemas de jogo que surgem. Uma das críticas inconsistentes a esse método é a necessidade de um maior tempo para que os aprendizes atinjam um alto nível de rendimento esportivo. Contudo, é necessário salientar que na fase de orientação (iniciação esportiva) o objetivo principal é que os aprendizes adquiram conhecimentos (meios) para se tornarem jogadores inteligentes; quer dizer, que eles sejam capazes (na fase de

Pensar a Prática, Goiânia, v. 14, n. 1, p. 1-18, jan./abr. 2011 
aproximação e alto nível ${ }^{5}$ ) de apresentar variadas respostas às imprevisibilidades dos jogos esportivos. Etapa da tríade do processo de ensino-aprendizagem-treinamento na qual os atletas devem responder adequadamente aos problemas que surgem no esporte coletivo, espera-se que nessa fase do sistema de formação esportiva eles não tenham suas ações (respostas) mecanizadas para uma determinada situação de jogo, como é mais provável de ocorrer com atletas que tiveram seu ensino-aprendizagem-treinamento com o método analítico.

Sendo assim, para a elaboração da proposta pedagógica foram utilizados parâmetros propostos por Kröger e Roth (2002), que são a utilização de jogos nos quais estejam presentes:

- "Peças táticas" relacionadas a acertar o alvo; transportar a bola ao objetivo; tirar vantagem tática no jogo; jogo coletivo; reconhecer espaços; superar adversários; oferecer-se e orientar-se;

- Jogos nos quais sejam encontradas condicionantes de pressão (pressão de tempo; pressão da precisão; pressão da complexidade; pressão da organização; pressão da variabilidade; pressão da carga.);

- Utilização de habilidades relacionadas a controle de ângulos para que haja precisão na direção de uma bola lançada; regulação de aplicação de força para que uma bola seja lançada precisamente; determinar o momento do passe, ou seja, promover a conscientização do momento espacial; determinar linhas de corrida e tempo de bola; oferecer-se para o jogo; antecipar a direção de um passe; antecipação defensiva; observação dos deslocamentos. Contudo, é válido dizer que, ao tratar da utilização das habilidades, não foi exigida a correção técnica desses gestos.

A faixa etária dos alunos foi considerada durante a elaboração da proposta pedagógica, entretanto é necessário salientar que as individualidades foram respeitadas, por acreditar-se que, mesmo integrando uma mesma faixa de idade, diferenças de desenvolvimento são possíveis e observadas. Assim sendo, foram utilizados como parâmetros para a elaboração da proposta os mesmos encontrados na "fase de orientação" (GRECO, 1995), sendo que nessa fase os jogos (situacionais) devem estar presentes com o intuito de embasar futuras atitudes táticas, ou seja, prover experiências que permaneçam na memória motora do aluno e sirvam para um comportamento tático inteligente dentro do jogo formal. Nessa fase também é importante que comecem a ser inseridos conteúdos técnicos do jogo, porém essa inserção não deve ser executada de forma analítica e sim integrada em diferentes tipos de jogos.

\footnotetext{
$5 \quad$ Fase de aproximação compreende a faixa etária de 18 a 21 anos e fase de alto nível compreende a faixa etária de 21 anos em diante (GRECO;BENDA, 1998, p. 77).
}

Pensar a Prática, Goiânia, v. 14, n. 1, p. 1-18, jan./abr. 2011 
Testes de habilidades

Para a avaliação do desenvolvimento dos alunos foram aplicados os testes propostos por Greco (1995), que consistem em avaliações da capacidade técnica e da capacidade tática dos aprendizes. São eles:

Teste de capacidade técnica

O teste de capacidade técnica, como o próprio nome indica, é um teste preconizado para avaliar no handebol a capacidade técnica de realização do drible (dribling e slalom), a capacidade técnica de arremesso (lançamento) e pontaria, capacidades necessárias para uma boa execução dos arremessos a gol e dos passes no handebol.

Dribling: o aluno driblando a bola deve percorrer, durante trinta segundos, o percurso completo de uma quadra de basquetebol. Será permitida uma só tentativa. O critério de avaliação foi o número de voltas e suas respectivas frações.

Slalom: o aluno, driblando a bola, deve percorrer, durante trinta segundos, o percurso em ziguezague delimitado por cones na quadra de handebol por uma extensão de dez metros com cones alinhados em intervalos de um metro. Foi permitida uma só tentativa. $\mathrm{O}$ critério de avaliação foi o número de voltas e suas respectivas frações.

Lançamento: o atleta deve realizar o maior número possível de repetições de arremesso, a uma distância de três metros, contra a parede, durante um único período de trinta segundos. $\mathrm{O}$ critério de avaliação foi o número total de repetições.

Teste de capacidade tática

O teste de capacidade tática, como o nome já sugere, é um teste preconizado para avaliar no handebol a capacidade tática dos alunos, ou seja, no teste descrito a seguir buscou-se avaliar a capacidade de percepção e tomada de decisão do aluno em relação às situações-problema colocadas pelos defensores. Assim, ao observar os sinais relevantes (braços altos, braços baixos, posição do goleiro, cobertura defensiva ou não, flutuação ou não do defensor) dos defensores, o atacante tinha que tomar a melhor decisão na situação apresentada e realizar um meio técnico-tático; o critério de avaliação para esse teste é considerar: índice 2, se o comportamento tático foi considerado correto; índice 1, se o comportamento tático foi considerado aceitável; índice zero, se o comportamento tático foi considerado errado.

Posição dos braços: o atleta recebia o passe efetuado por um colaborador e, no movimento de engajamento, observava a ação do defensor buscando "sinais relevantes". Por exemplo: "braços abaixados" significam a indicação favorável a um arremesso em suspensão, "braços no alto" indicam a realização de um arremesso com apoio à altura dos quadris. Dois colaboradores foram requisitados para essa atividade: enquanto um efetuava o passe para o atacante no movimento de engajamento, o outro atuava como defensor próximo à linha de seis metros. O defensor deveria manter seus braços abaixados ou

Pensar a Prática, Goiânia, v. 14, n. 1, p. 1-18, jan./abr. 2011 
levantados no momento em que o atacante realizava seu $3^{\circ}$ passo. A atitude do defensor era realizada de forma aleatória. $\mathrm{O}$ atacante teve apenas uma tentativa. Os demais alunos foram mantidos afastados de modo que não observavam o desenvolvimento do teste do seu colega. Cada atleta recebia orientação sobre o teste no momento prévio à sua execução.

Pontaria com goleiro: o atleta partia, driblando a bola da metade da quadra e a lançava - em suspensão - ao gol de uma distância de nove metros. Um colaborador, no meio do gol, esperava o atleta apoiar o terceiro passo para deslocar-se para um canto, simulando a atitude de um goleiro que "escolhe um lado". O lançamento dirigido ao setor contrário à posição do goleiro, no ângulo, era avaliado com dois pontos; com um ponto o lançamento realizado no setor contrário ao goleiro, sem precisão; e com zero ponto o lançamento desviado. Os lançamentos realizados no mesmo setor do goleiro receberam igualmente zero ponto.

Penetração: dois defensores (representados por dois colaboradores) foram colocados na área do goleiro, separados lateralmente, três metros entre si. $\mathrm{O}$ aluno recebia $\mathrm{o}$ passe no movimento de engajamento e deveria decidir conforme a ação dos defensores: se os dois fechassem o espaço entre eles, faria a devolução do passe ao colega; se os defensores permanecessem separados entre si, próximos à linha de seis metros, faria a penetração e o lançamento (arremesso). O sinal era dado pelos defensores no momento de recepção da bola, durante o engajamento. $\mathrm{O}$ atacante teve apenas uma tentativa.

Finta: um colaborador efetuava a função de defensor e um segundo executava o passe. $\mathrm{O}$ atacante deveria, no movimento do engajamento, observar a atitude do defensor e decidir por realizar a finta ou diretamente o arremesso. A finta correspondia à resposta adequada, quando o defensor saía para efetuar a marcação na linha de nove metros (realizava a flutuação); o lançamento correspondia à resposta adequada quando o defensor ficava em linha de seis metros. O sinal era dado no momento da recepção do passe pelo atacante, durante o engajamento. $\mathrm{O}$ atacante teve apenas uma tentativa.

Descritos os testes, é importante dizer que eles foram aplicados na $3^{\text {a }}$ sessão de treinamento e que foram realizados registros destes, em um caderno de campo, assim como sobre o desempenho individual dos alunos em cada uma das sessões. A segunda forma de análise do desempenho dos alunos nas aulas foi baseada nos indicadores e fatores da qualidade do jogo e nas fases de jogo, propostos por Garganta (1995), que são:

- Indicadores do jogo de nível fraco:

○ aglutinação em torno da bola

$\circ$ individualismo

○ não buscar espaços para facilitar a recepção de um passe

○ não defender

- verbalização excessiva

○ desrespeito às decisões da arbitragem

- Fatores de desenvolvimento de um bom jogo:

○ passar a bola

Pensar a Prática, Goiânia, v. 14, n. 1, p. 1-18, jan./abr. 2011 
○ afastar-se do colega que possui a bola

- buscar espaços para recepção da bola

○ intencionalidade (leitura do jogo)

- ação após passe (movimentação para restabelecimento de linha de passe)

- aclaramento (afastar-se do possuidor da bola e ocupar seu espaço)

○ foco no objetivo do jogo (gol)

Com base nesses indicadores, foram estabelecidas, também por Garganta (1995), as fases de desenvolvimento do jogo:

- Jogo Anárquico: foco excessivo na bola e aglutinação em torno desta; problemas na compreensão do jogo; abuso da verbalização; elevada utilização da visão central.

- Descentração: a função não depende exclusivamente da posição da bola; prevalência da verbalização; ocupação de espaço em função dos elementos do jogo; transição da visão central para periférica.

- Estruturação: conscientização da coordenação das funções; verbalização e surgimento da comunicação gestual; ocupação racional do espaço; passagem do controle visual para o proprioceptivo.

- Elaboração: ações inseridas na estratégia da equipe; comunicação motora; polivalência funcional e coordenação das ações táticas; otimização de capacidades proprioceptivas.

Para a análise, foram utilizados os dados de sete sujeitos que executaram o pré-teste e o pós-teste. Tendo esses parâmetros em foco, foram utilizadas para a análise as anotações do desempenho em cada sessão.

$\mathrm{O}$ teste estatístico utilizado foi TTest Unicaudal, para amostras pareadas e paramétricas. $\mathrm{O}$ valor de referência significativa considerado foi o de $\mathrm{P}<0,05$, sendo que esse teste estatístico foi utilizado na comparação dos valores entre os dados obtidos nos pré e pós-testes de capacidade técnica, analisando se houve ou não diferenças significativas.

\section{Resultados}

A frequência do grupo apresentou grande variação, no total foram 32 sessões de treinamento ministradas. Encontrou-se uma média de comparecimento deles em aproximadamente 25 sessões. Na tabela I são apresentados os valores da frequência de cada sujeito e a média da frequência do grupo.

Pensar a Prática, Goiânia, v. 14, n. 1, p. 1-18, jan./abr. 2011 
Tabela I: Frequência dos sujeitos $(1,2,3,4,5,6$ e 7) e média de comparecimento destes às sessões.

\begin{tabular}{ccccccccc}
\hline Sujeitos & $\mathbf{1}$ & $\mathbf{2}$ & $\mathbf{3}$ & $\mathbf{4}$ & $\mathbf{5}$ & $\mathbf{6}$ & $\mathbf{7}$ & Média \\
\hline $\begin{array}{c}\text { Número de } \\
\text { sessões }\end{array}$ & 22 & 31 & 28 & 26 & 31 & 12 & 24 & 24,8 \\
\hline
\end{tabular}

A Tabela II apresenta os resultados dos testes referentes ao dribling, slalom e lançamento, obtidos nos pré e pós-testes.

Tabela II: Resultados dos testes técnicos, indicando os valores obtidos nos pré e pós-testes.

\begin{tabular}{ccccccc}
\hline $\begin{array}{c}\text { Testes } \\
\text { Sujeitos }\end{array}$ & \multicolumn{2}{c}{ Dribling $(\mathbf{m})$} & \multicolumn{2}{c}{ Slalom $(\mathbf{m})$} & \multicolumn{2}{c}{ Lançamento $(\mathbf{n})$} \\
Pré & Pós & Pré & Pós & Pré & Pós \\
\hline $\mathbf{1}$ & 96 & 90 & 30 & 20 & 15 & 21 \\
$\mathbf{2}$ & 81 & 90 & 24 & 30 & 14 & 15 \\
$\mathbf{3}$ & 109 & 110 & 38 & 30 & 20 & 24 \\
$\mathbf{4}$ & 90 & 90 & 37 & 29 & 19 & 23 \\
$\mathbf{5}$ & 117 & 117 & 36 & 33 & 20 & 20 \\
$\mathbf{6}$ & 102 & 72 & 22 & 22 & 13 & 7 \\
$\mathbf{7}$ & 107 & 81 & 37 & 14 & 14 & 11 \\
\hline
\end{tabular}

Não foram encontradas diferenças significativas $(\mathrm{p}<0,05)$ para nenhum dos testes, com a observação de uma tendência de aumento para o teste de lançamento, e uma tendência de queda para os testes de dribling e slalom. A Figura 1 mostra os boxplots com os respectivos intervalos de confiança da mediana dos testes de dribling, slalom e lançamento, indicados pelo chanfro em cada boxplot (McGILL;TUKEY;LARSEN, 1978).

Pensar a Prática, Goiânia, v. 14, n. 1, p. 1-18, jan./abr. 2011 

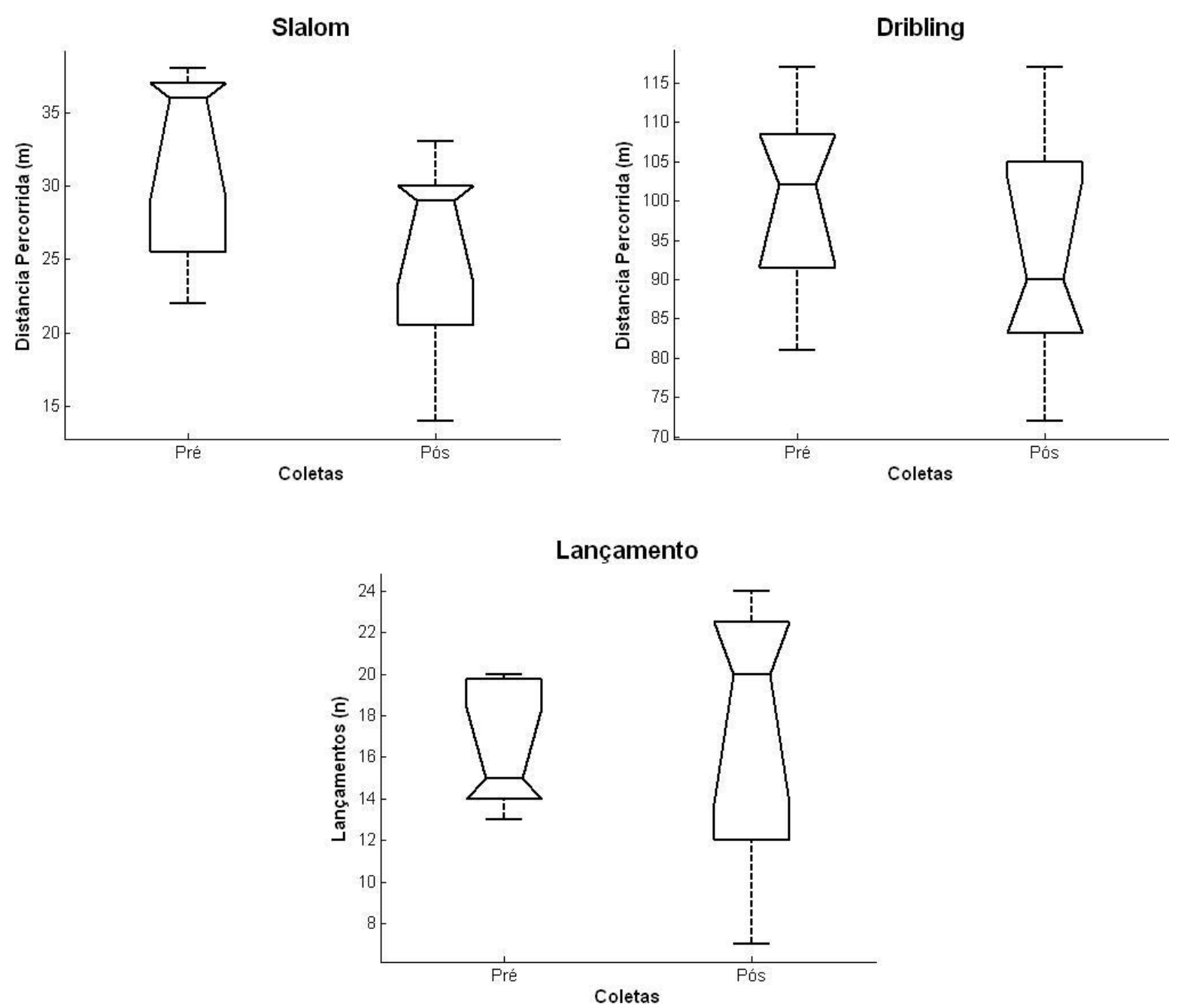

Figura 1: Boxplots com intervalo de confiança da mediana dos resultados obtidos nos testes de dribling, slalom e lançamentos.

Na Tabela III são apresentados os resultados dos testes táticos referentes às provas de pontaria com o goleiro, posição dos braços, penetração e finta, tanto para o pré-teste quanto para o pós-teste.

Pensar a Prática, Goiânia, v. 14, n. 1, p. 1-18, jan./abr. 2011 
Tabela III: Resultados dos testes táticos, em que o índice 0 representa resposta errada, o índice 1 representa resposta aceitável e o índice 2 representa resposta correta.

\begin{tabular}{c|cc|cc|cc|cc}
\hline \multirow{2}{*}{$\begin{array}{c}\text { Testes } \\
\text { Sujeitos }\end{array}$} & \multicolumn{2}{|c|}{$\begin{array}{c}\text { Pontaria com } \\
\text { goleiro }\end{array}$} & \multicolumn{2}{c|}{$\begin{array}{c}\text { Posição dos } \\
\text { Braços }\end{array}$} & \multicolumn{2}{c|}{ Penetração } & \multicolumn{2}{c}{ Finta } \\
\hline 1 & 1 & 1 & 0 & 2 & 1 & 2 & 1 & 0 \\
2 & 1 & 2 & 1 & 2 & 1 & 1 & 2 & 0 \\
3 & 0 & 2 & 0 & 2 & 1 & 2 & 0 & 2 \\
4 & 0 & 1 & 1 & 1 & 0 & 2 & 2 & 2 \\
5 & 0 & 2 & 2 & 2 & 2 & 2 & 1 & 2 \\
6 & 0 & 0 & 2 & 0 & 0 & 1 & 2 & 1 \\
7 & 0 & 1 & 0 & 1 & 2 & 2 & 0 & 2 \\
\hline
\end{tabular}

No teste de Pontaria com o goleiro, foram encontrados os seguintes resultados:

- No pré-teste:

- Cinco alunos $(71,5 \%)$ obtiveram índice 0 ;

- Dois alunos obtiveram índice $1(28,5 \%)$;

- Nenhum aluno obteve índice $2(0 \%)$.

- No pós-teste:

- Um aluno obteve índice $0(14 \%)$;

- Três alunos obtiveram índice $1(43 \%)$;

- Três alunos (43\%) obtiveram índice 2 .

Na Figura 2 está representado o gráfico de distribuição de ocorrências em pré e pósteste para os índices 0,1 e 2 .

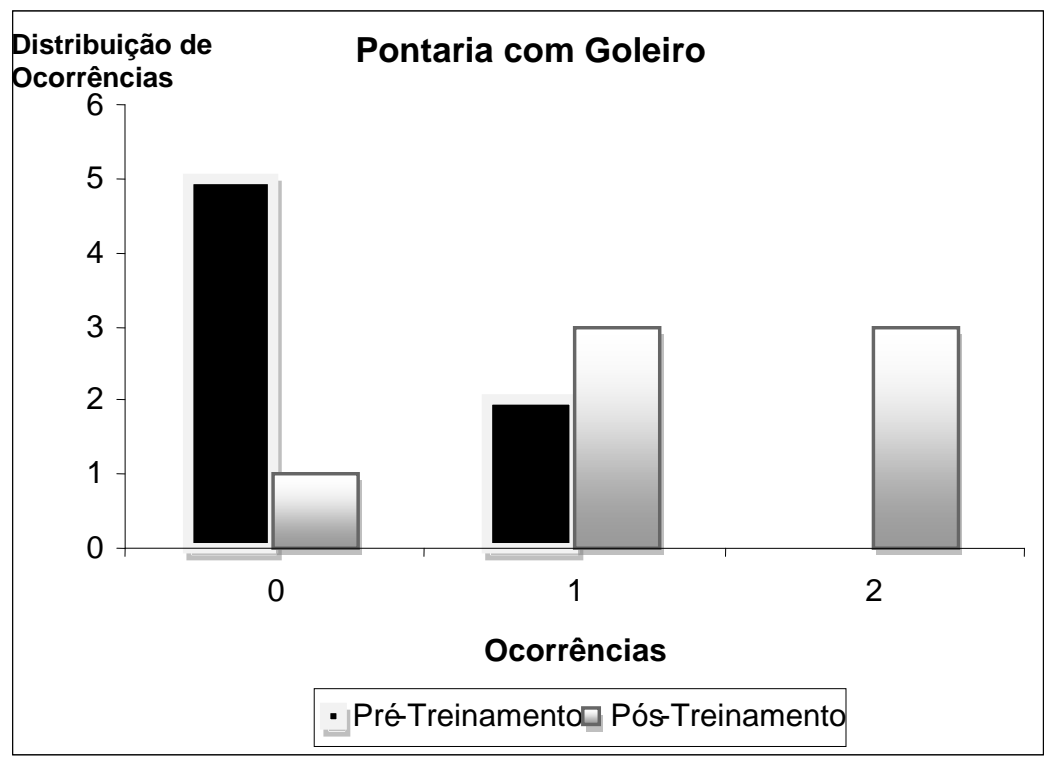

Figura 2: Distribuição dos índices de ocorrências (pontuação) no pré e no pós-teste de pontaria com goleiro.

Pensar a Prática, Goiânia, v. 14, n. 1, p. 1-18, jan./abr. 2011 
No teste de Posição dos braços, os seguintes resultados foram encontrados:

- No pré-teste:

- Três alunos obtiveram índice 0 (43\%);

- Dois alunos obtiveram índice $1(28,5 \%)$;

- Dois alunos obtiveram índice $2(28,5 \%)$.

- No pós-teste:

- Um aluno obteve índice 0 (14\%);

- Dois alunos obtiveram índice $1(28,5 \%)$;

- Quatro alunos obtiveram índice $2(57,5 \%)$.

Na Figura 3, está representado o gráfico de distribuição de ocorrências em pré e pós-teste para os índices 0,1 e 2 .

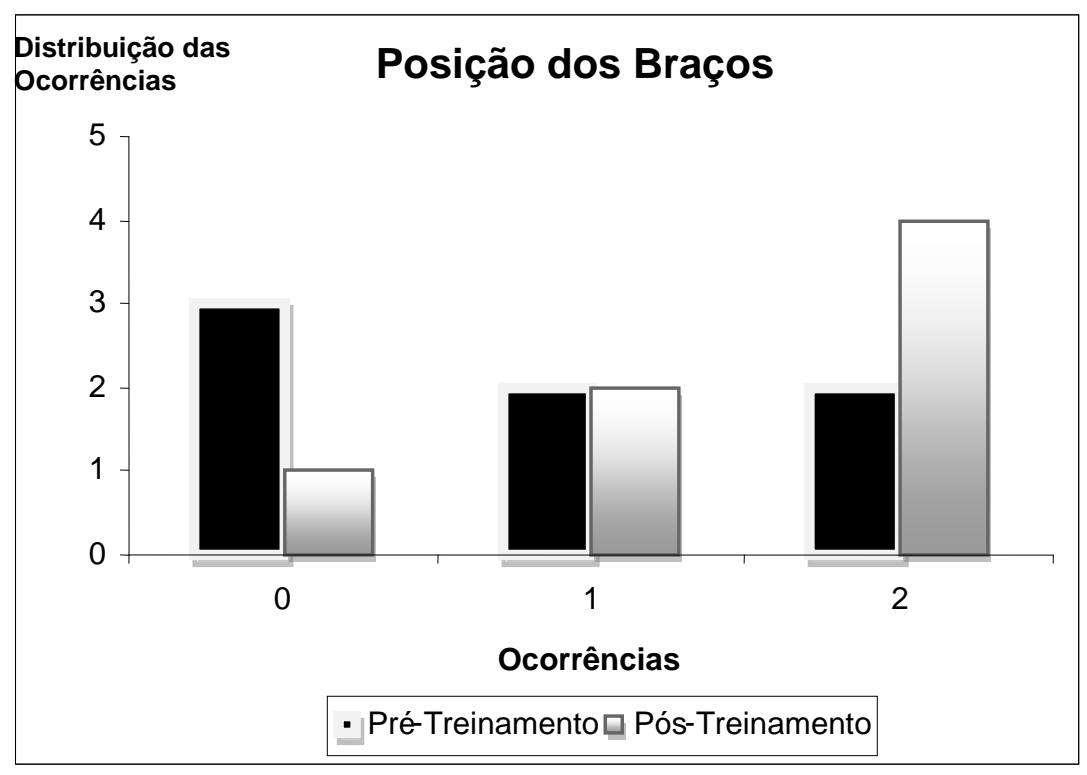

Figura 3: Distribuição dos índices de ocorrências (pontuação) no pré e no pós-teste de posição dos braços

No teste de Penetração foram encontrados os seguintes resultados:

- No pré-teste:

- Dois alunos obtiveram índice $0(28,5 \%)$;

- Três alunos obtiveram índice 1 (43\%);

- Dois alunos obtiveram índice $2(28,5 \%)$.

- No pós-teste:

- Nenhum aluno obteve índice $0(0 \%)$;

- Dois alunos obtiveram índice $1(28,5 \%)$;

Pensar a Prática, Goiânia, v. 14, n. 1, p. 1-18, jan./abr. 2011 
- Cinco alunos obtiveram índice 2 (71,5\%).

Na Figura 4, está representado o gráfico de distribuição de ocorrências em pré e pós-teste para os índices 0,1 e 2 .

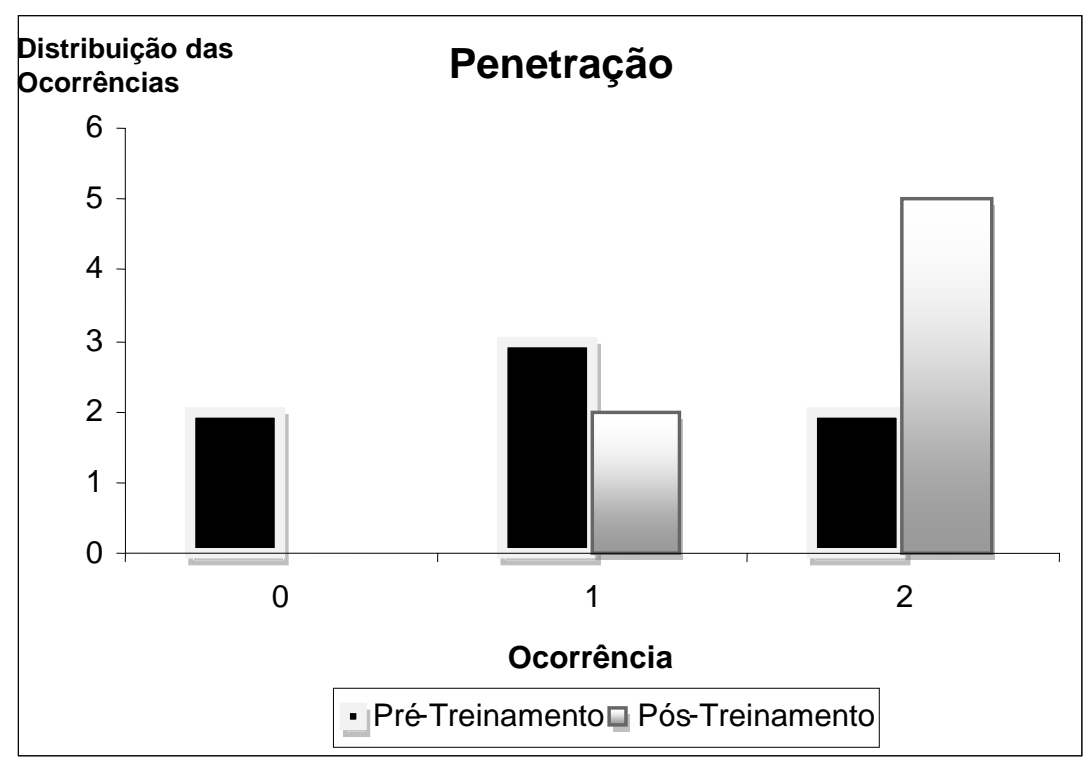

Figura 4: Distribuição dos índices de ocorrências (pontuação) no pré e no pós-teste de penetração

No teste de Finta foram encontrados os seguintes resultados:

- No pré-teste:

- Dois alunos obtiveram índice $0(28,5 \%)$;

- Dois alunos obtiveram índice $1(28,5 \%)$;

- Três alunos obtiveram índice 2 (43\%).

- No pós-teste:

- Dois alunos obtiveram índice $0(28,5 \%)$;

- Um aluno obteve índice 1 (14\%);

- Quatro alunos obtiveram índice $2(57,5 \%)$.

Na Figura 5, está representado o gráfico de distribuição de ocorrências em pré e pós-teste para os índices 0,1 e 2 .

Pensar a Prática, Goiânia, v. 14, n. 1, p. 1-18, jan./abr. 2011 


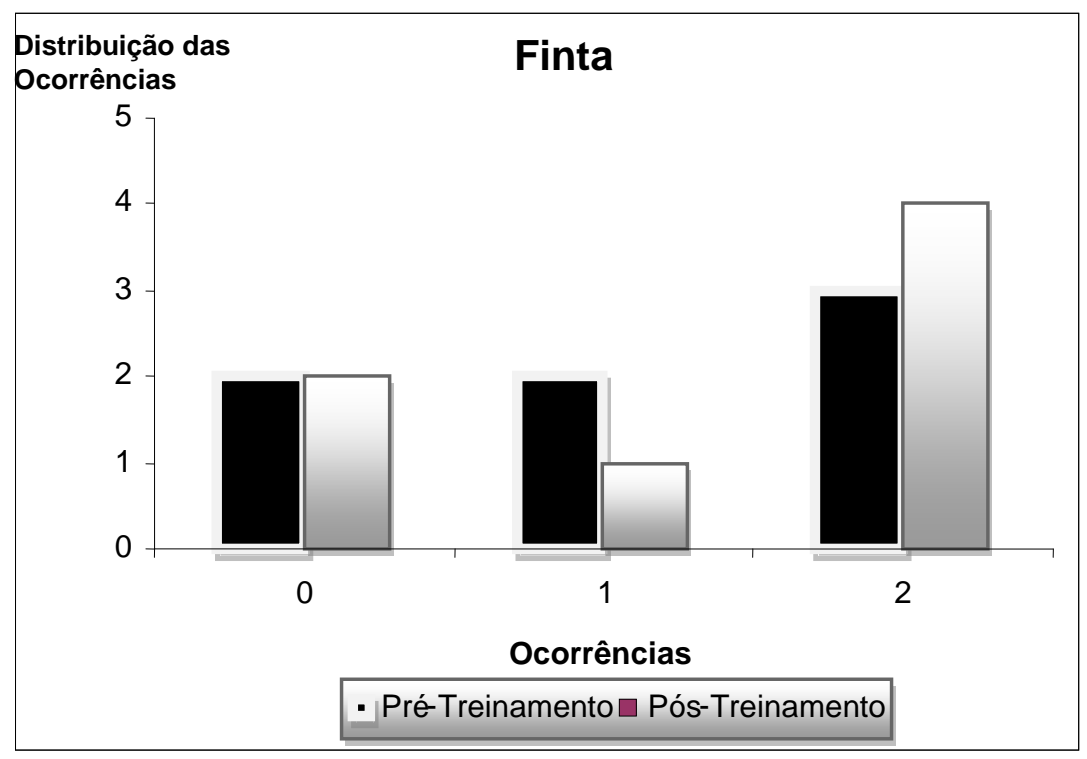

Figura 5: Distribuição dos índices de ocorrências (pontuação) no pré e no pósteste de finta.

A partir dos registros no caderno de campo, pôde ser observado que, inicialmente, os primeiros jogos executados pelos alunos tinham como característica a aglutinação em torno da bola, sem a preocupação da ocupação homogênea dos espaços para o surgimento de linhas de passe; apresentavam ainda abuso de ações individuais e um rápido desinteresse relacionado às ações defensivas. Segundo Garganta (1995), esses comportamentos são indicadores de jogo de nível fraco que caracterizam o "jogo anárquico".

\section{Discussão}

Para os testes de capacidade técnica, o tratamento estatístico não apontou diferenças significativas entre o pré e o pós-teste. Porém, em uma análise qualitativa baseada na observação do desempenho dos alunos e mesmo nos dados apresentados na Tabela II, é possível apontar as seguintes variações entre pré e pós-testes:

- Teste de dribling: dois alunos melhoraram, dois mantiveram seus resultados e três pioraram a capacidade de drible;

- Teste de slalom: um aluno melhorou, um aluno manteve o resultado e cinco pioraram;

- Teste de lançamento: quatro alunos melhoraram, um aluno manteve e dois alunos pioraram a capacidade de pontaria de passes e arremessos.

Uma das possíveis explicações para esses resultados está fundada no fato de que as atividades do processo pedagógico estimularam os arremessos ao gol, com oponente, e uma alta frequência das atividades de passes. Em contrapartida, o drible não foi tão estimulado

Pensar a Prática, Goiânia, v. 14, n. 1, p. 1-18, jan./abr. 2011 
assim, tendo em vista que o jogo formal de handebol é um jogo veloz e de passes e que apresenta poucas situações de drible.

Para os quatro testes táticos, os resultados dos pré e pós-testes foram distribuídos da seguinte maneira:

- Pré-testes:

○ Índice 0: 13 ocorrências;

○ Índice 1: oito ocorrências;

○ Índice 2: sete ocorrências.

- Pós-testes:

○ Índice 0: quatro ocorrências;

- Índice 1: oito ocorrências;

○ Índice 2: 16 ocorrências.

Diante dos resultados apresentados, e baseando-se na proposta metodológica aplicada, os índices apresentaram tendência de melhores resultados com redução na ocorrência de índice zero, manutenção na quantidade de índices 1, aumento na ocorrência de índice 2. Se considerarmos os resultados gerais obtidos nos testes táticos, é possível afirmar que cinco alunos melhoraram sua capacidade tática geral e dois alunos a mantiveram.

Relacionando esses dados às funções de resolução, compreensão e efetuação (GARGANTA;OLIVEIRA, 1996) e ao desenvolvimento tático do grupo, foi observado que, após a aplicação da proposta pedagógica, os alunos: a) apresentaram domínio de um maior número de respostas táticas às situações-problema propostas (função de resolução); b) aplicaram essas respostas às situações de forma coerente (função de compreensão); e c) tomaram a iniciativa de resposta de forma mais dinâmica e eficaz (função de efetuação).

Como exemplo, pode ser citada a conduta dos alunos em uma atividade de $2 \times 1$, jogada em toda a extensão da quadra, com proibição de drible, na qual os atacantes tentavam marcar o gol, e o defensor tentava impedi-los. Nas primeiras sessões de treinamento, o atacante que não possuía a bola se posicionava estaticamente, não permitindo a formação de uma linha de passe. No decorrer dos treinos, quando da reaplicação da atividade, notou-se que esse atacante, que antes se apresentava de forma estática, passou a movimentar-se (e a desmarcar-se) possibilitando a continuidade do jogo ofensivo. Essas situações de jogo, seja em igualdades ou em desigualdades numéricas, devem estar presentes constantemente nas sessões de treinamentos, em que "múltiplas soluções [...] devem ser buscadas pelos jogadores" (MENEZES, 2010, p.13).

O mesmo tipo de comportamento tático pôde ser observado quando da aplicação de jogos com equipes em igualdade numérica, atestando para a melhoria das funções de resolução (criação da hipótese de movimentar-se para formar a linha de passe), compreensão (compreender a hipótese e encará-la como a mais válida) e de efetuação (decidir-se e executar a hipótese). Esse fato pode estar relacionado à afirmação de Araújo (2003, p.91), com relação à ação tática, que é tida como "integrante do processo comportamental de resolução de problemas num contexto de jogo".

Pensar a Prática, Goiânia, v. 14, n. 1, p. 1-18, jan./abr. 2011 
Dessa forma, e conforme o esperado, notou-se que o método aplicado não promoveu ganhos na capacidade técnica dos alunos, devido à sua concepção (aumentar a capacidade tática dos alunos). Outro fator a ser ressaltado faz alusão ao drible, que, por não ter uma exigência muito frequente no jogo de handebol (ao comparado com o passe e com o arremesso), seria medido diferentemente, justificando-se pelo fato de que sua proibição, em alguns jogos na iniciação ao handebol, visa aumentar a participação de todos os jogadores naquele jogo e o aperfeiçoamento dos passes.

Os resultados encontrados por nós quanto à melhora do comportamento tático no jogo de handebol após a aplicação do método situacional também foi observado por Pinho, Alves, Greco e Schild (2010) em pesquisa com estudantes entre 10 e 12 anos de idade que se submeteram à aprendizagem do handebol por meio desse método.

\section{Conclusão}

O método utilizado para o ensino-aprendizagem-treinamento da modalidade handebol teve como procedimentos pedagógicos a utilização de processos inconscientes, ensino incidental, priorizando a aquisição de conhecimento tático que capacite a solução de problemas, sem uma preocupação de aplicação da técnica dos gestos técnicos específicos da modalidade com maestria. Para o método situacional, após os treinos com as situações novas, o aluno deve adaptar-se e assimilar cognitivamente estas, tornando-as já conhecidas e aumentando sua bagagem de soluções de problemas nas situações enfrentadas e nas soluções experimentadas.

Com a aplicação desse método, ficou evidenciado o aumento do repertório de soluções táticas dos alunos ante a imprevisibilidade inerente aos jogos esportivos coletivos, ou seja, eles passaram a ter um comportamento tático mais inteligente, podendo responder a uma maior quantidade de situações.

A partir da aplicação do pré e pós-testes técnicos, não foi encontrada diferença estatisticamente significativa ( $\mathrm{p}<0,05)$, com tendência de diminuição nos valores obtidos nos testes de slalom e dribling e com tendência a aumento no teste de lançamento. Considerando esse fato, foi observado que o método não implicou melhoria técnica significativa dos alunos e nem em uma queda significativa de seus níveis técnicos iniciais.

Sendo assim, fica demonstrado que o método de ensino-aprendizagem-treinamento utilizado permitiu aos alunos a aprendizagem do jogo de modo incidental, sem pressões de melhoria técnica, a partir da experimentação por eles de diferentes situações táticas, e do entendimento delas para a tomada de decisão.

\section{Referências}

ARAÚJO, D. A auto-organização da acção táctica: comentário a Costa, Garganta, Fonseca e Botelho (2002). Revista Portuguesa de Ciências do Desporto, v. 3, n. 3, p. 87-93, 2003.

FALKOWSKI, M. M. Táctica y Sistemas de Juego: Volumen 1 Táctica Ofensiva Individual. Librería Deportiva Esteban Sanz, 1979.

Pensar a Prática, Goiânia, v. 14, n. 1, p. 1-18, jan./abr. 2011 
GARGANTA, J.; OLIVEIRA, J. Estratégia e tática nos jogos esportivos. Porto: Centro de Estudos dos Jogos Esportivos/Universidade do Porto, 1996.

GARGANTA, J. M. Para uma teoria dos jogos desportivos colectivos. In: GRAÇA, A.; OLIVEIRA, J. (Orgs.). O ensino dos jogos desportivos. 2.ed. Porto: Faculdade de Ciências do Desporto e de Educação Física, 1995.

GRAÇA, A. Os comos e os quandos no ensino dos jogos. In: GRAÇA, A.; OLIVEIRA, J. (Orgs.). O ensino dos jogos desportivos. 2.ed. Porto: Faculdade de Ciências do Desporto e de Educação Física, 1995.

GRECO, P. J. Hándbal: la formación de jugadores inteligentes de balonmano. Stadium, Buenos Aires, n. 128, p. 22-27, abr.1988.

GRECO, P. J. O ensino do comportamento tático nos jogos esportivos coletivos: aplicação no handebol. 1995. 224f. Tese (Doutorado) - FE/UNICAMP, Campinas, 1995.

GRECO, P. J.; BENDA, R. N. Iniciação Esportiva Universal. Vol. 1. Da aprendizagem motora ao treinamento técnico. Belo Horizonte: Ed. Universitária UFMG, 1998.

GRECO, P. J. Tática e processos cognitivos subjacentes à tomada de decisão nos Jogos Esportivos Coletivos. In: GARCIA, E.; LEMOS, K. (Orgs.). Temas Atuais V em Educação Física e Esportes. Belo Horizonte: Saúde Ltda., 2000a, p. 11-27.

GRECO, P. J. Métodos de ensino-aprendizagem-treinamento nos jogos esportivos coletivos. In: GARCIA, E.; LEMOS, K. (Orgs.). Temas Atuais VI em Educação Física e Esportes. Belo Horizonte: Saúde Ltda., 2000b, p. 48-72.

KRÖGER, C.; ROTH, K. Escola da Bola: um ABC para iniciantes nos jogos esportivos. São Paulo: Phorte, 2002.

McGILL, R.; TUKEY, J. W.;LARSEN, W. A. Variations of Box Plots. The American Statistician, v. 32, n. 1, p. 12-16, fev, 1978.

MENEZES, R. P. O ensino dos sistemas defensivos do handebol: considerações metodológicas acerca da categoria cadete. Pensar a Prática, v. 13, n. 1, p. 1-16, 2010.

PAES, R. R. Educação Física Escolar: o esporte como conteúdo pedagógico no ensino fundamental. Canoas: Ed. ULBRA, 2001.

Pensar a Prática, Goiânia, v. 14, n. 1, p. 1-18, jan./abr. 2011 
PINHO, S. T.; ALVES, D. M.; GRECO, P. J.; SHILD, J.F.G. Método situacional e sua influência no conhecimento tático processual de escolares. Motriz, v. 16, n. 3, p. 580-590, 2010.

\title{
EVALUATION OF HANDBALL LEARNING ON YOUNG PEOPLE FROM 11 TO 14 YEARS USING THE SITUATIONAL METHOD
}

\begin{abstract}
The situational method is not based on technical mastery, but the tactic of team sports, making the players got used to the situations of the game, so they'll have many ways to resolve them, chosing always the best way. This study aimed to assess the influences of the situational method in the technic and tactics using the tests proposed in Greco (1995) and also through the game levels proposed by Garganta (1995). After the method application an improvement of the tactical ability and stagnation on the techcnical ability were observed, demonstrating methodology effectiveness.
\end{abstract}

Keywords: Team Sports - Handball - Situational

Endereço para correspondência:

Heloisa Helena Baldy dos Reis

helobaldy@yahoo.com

Universidade Estadual de Campinas

Faculdade de Educação Física, Departamento de Estudos do Lazer.

Rua Érico Veríssimo, 701

Cid. Universit. Zeferino Vaz

13083-970 - Campinas, SP - Brasil - Caixa-Postal: 6134

Pensar a Prática, Goiânia, v. 14, n. 1, p. 1-18, jan./abr. 2011 